\title{
Gastrointestinal Stromal Tumor - An Overview
}

\begin{abstract}
Gastrointestinal stromal tumors (GISTs) are rare tumors but are most common mesenchymal tumors of the digestive tract. They are commonly seen in the stomach $(60 \%)$ and small intestine $(30 \%)$. GISTs are likely derived from the interstitial cells of Cajal or their stem cell precursors. They are best characterized by computerized tomography and have a specific staining pattern on immunohistochemistry, i.e., C-Kit and DOG-1. The treatment of GIST is based on the risk assessment for relapse, and patients with localized GIST require resection with or without adjuvant imatinib mesylate (IM). Advanced unresectable tumors are usually treated with IM, with a number of further options available for patients post progression on IM. There is an increasing emphasis on identifying C-Kit and platelet-derived growth factor receptor alpha mutations in all patients with GIST, as these are driver mutations with current and future therapeutic implications.
\end{abstract}

\section{Keywords: Gastrointestinal stromal tumor, Indian data, overview}

\section{Introduction}

Gastrointestinal stromal tumors (GISTs), in general, are rare tumors but they are the most common mesenchymal tumors of the digestive tract and rarely can arise from the intra-abdominal soft tissues. ${ }^{[1]}$ They are commonly seen in the stomach $(60 \%)$ and small intestine $(30 \%)$ but are also seen in the rectum and colon. ${ }^{[2,3]}$ The discovery of the c-KIT gene (cellular homolog of the oncogene v-KIT) set the ball rolling in elucidation of the pathogenesis of GIST as well as its classification as a separate disease entity. ${ }^{[4,5]}$

\section{Global Incidence, Epidemiology - Global and India}

The global incidence of GIST is unknown due to the rarity of the disease, but available data suggest variances across geographical regions. Reported incidence from Northern Norway, Hong Kong, and Korea is approximately 9-22 cases per million inhabitants, while incidences are lower from North America, Slovakia, etc., (4.3-6.8 cases per million). ${ }^{[6]}$ Although GISTs can arise at any age, they are most commonly seen beyond the age of 50 years (median age -63 years). There is no large scale data from India with regard

This is an open access journal, and articles are distributed under the terms of the Creative Commons Attribution-NonCommercial-ShareAlike 4.0 License, which allows others to remix, tweak, and build upon the work non-commercially, as long as appropriate credit is given and the new creations are licensed under the identical terms.

For reprints contact:WKHLRPMedknow_reprints@wolterskluwer.com to the incidence or clinical presentation. Small single-institution studies have shown a median age range at a diagnosis of 50-58 years, with a greater incidence of presentation with advanced/metastatic disease, though this is possibly due to underreporting of early cases. ${ }^{[7,8]}$

\section{Clinical Presentation - Global and India}

Approximately $18 \%-25 \%$ of patients have been diagnosed with GIST based on imaging or while being investigated for other illnesses. The most common site is the stomach $(60 \%)$, but GISTs can be found throughout the gastrointestinal (GI) tract including the jejunum and ileum $(30 \%)$, duodenum $(5 \%)$, colon/rectum (4\%), and esophagus or appendix $(<1 \%)$. Occasionally, complications such as hemorrhage, tumor rupture, bowel perforation, or obstruction. The increased awareness of GIST as a different disease with improved diagnostic criteria and routine use of adjuvant imatinib have resulted in the pickup of smaller tumors at the diagnosis of GIST. This has resulted in a new subgroup of GISTs called mini-GISTs (measuring between 1 and $2 \mathrm{~cm}$ ) and micro-GISTs (measuring $<1 \mathrm{~cm}$ ).

GISTs are rare in the pediatric age group, and most of them are observed in the second decade with a female predisposition.

How to cite this article: Ramaswamy A, Chaudhari V, Bhargava P, Bhandare M, Kumar R, Shrikhande SV, et al. Gastrointestinal stromal tumor - An overview. Indian J Med Paediatr Oncol 2020;41:809-18. they may present with emergent
Anant

Ramaswamy ${ }^{1}$, Vikram Chaudhari², Prabhat Bhargava1, Manish Bhandare ${ }^{2}$, Rajiv Kumar ${ }^{3}$, Shailesh V Shrikhande ${ }^{2}$, Vikas Ostwal ${ }^{1}$

${ }^{1}$ Department of Medical Oncology, Tata Memorial Hospital, Homi Bhabha National Institute (HBNI), Mumbai, Maharashtra, India, ${ }^{2}$ GI and HPB Surgery, Department of Surgical Oncology, Tata Memorial Hospital, Homi Bhabha National Institute, Mumbai, Maharashtra, India, ${ }^{3}$ Department of Pathology, Tata Memorial Hospital, Homi Bhabha National Institute, Mumbai, Maharashtra, India

Submitted: 05-Feb-2020 Revised: 05-Mar-2020 Accepted: 10 -Apr-2020 Published: 31-Dec-2020

Address for correspondence:

Dr. Vikas Ostwal,

Department of Medical Oncology, Tata Memorial Hospital, Homi Bhabha National Institute (HBNI), Mumbai, Maharashtra, India. E-mail:drvikas.ostwal@gmail. com

Access this article online

Website: www.ijmpo.org

DOI: 10.4103/ijmpo.ijmpo_45_20 Quick Response Code:

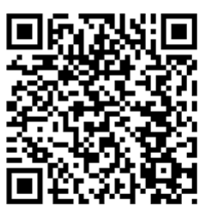


They almost exclusively arise in the stomach with frequent nodal involvement in this age group. ${ }^{[9]}$

A snapshot of Indian data with regard to epidemiology and presentation is presented in Table $1 .{ }^{[7-13]}$

\section{Molecular Basis of Gastrointestinal Stromal Tumor}

The central role in the pathogenesis of GIST is occupied by the KIT and platelet-derived growth factor receptor alpha (PDGFRA) genes. These genes encode tyrosine kinase receptors comprising an extracellular ligand-binding region, a transmembrane sequence, a juxtamembrane domain, and two cytoplasmic kinase domains. ${ }^{[14]}$ Mutations in KIT and PDGFRA result in constitutive activation and signaling (in the absence of the endogenous ligand) causing a chain of cellular events, leading to the advent of GIST. A majority of mutations are seen in the KIT gene (approximately $80 \%$, predominantly juxtamembrane) and found in exon $11(70 \%)$ and exon $9(10 \%) \cdot{ }^{[1,15]}$ Mutations in the exon 11 themselves are a heterogeneous group, with mutations in codon 557-558 of exon 11 having a different biological behavior compared to other exon 11 mutants. ${ }^{[16-18]}$ PDGFRA mutations are seen in $<10 \%$ of GISTs, primarily either exon 18 or 14. GISTs with PDGFRA mutations are considered less aggressive compared to KIT-mutant GISTs.
Approximately $10 \%$ of all GISTs are considered "wild type" and are characterized by the absence of KIT and PDGFRA mutations. However, targeted exome sequencing analyses in this "wild type" cohort have identified germ line mutations involving succinate dehydrogenase (SDH), resulting in a complete loss or reduction in $\mathrm{SDH}$ protein, thereby causing GIST. ${ }^{[19]}$

\section{Evaluation and Workup}

Although GISTs may often be diagnosed incidentally, once suspected, a complete diagnostic evaluation is essential.

a. Endoscopy and endoscopic ultrasound (EUS) - Since small GISTs are often evaluated initially as submucosal tumors, the initial investigation for such tumors would be an EUS-fine-needle aspiration (FNA). ${ }^{[20]}$ EUS-FNA is indicated for lesions measuring $>1 \mathrm{~cm}$ (usually between 1 and $2 \mathrm{~cm}$ ) that are suspected to be potentially malignant ${ }^{[21]}$. For larger tumors of the stomach (potential candidates for resection), an endoscopy is an ideal investigation for description of the tumor as well as taking adequate biopsies

b. Radiology and Nuclear imaging - The imaging modality of choice for accurate detection and staging of a GIST in the current era is a contrast-enhanced computerized tomographic (CECT) scan. Since GISTs normally arise

\begin{tabular}{|c|c|c|c|c|c|}
\hline Centre & $\begin{array}{c}\text { Number of } \\
\text { patients }\end{array}$ & Median age & Common sites & Presentation & Highlights \\
\hline NIMS, Hyderabad $^{[7]}$ & 50 & 50 & $\begin{array}{l}\text { Stomach } \\
\text { Jejunum } \\
\text { Colon }\end{array}$ & $\begin{array}{l}60 \% \text { curative } \\
\text { resection }\end{array}$ & $\begin{array}{l}\text { Differences in outcomes between } \\
\text { intermediate and high risk }\end{array}$ \\
\hline CMC, Vellore ${ }^{[8]}$ & 92 & $4^{\text {th }}-5^{\text {th }}$ decade & $\begin{array}{l}\text { Small intestine } \\
\text { Stomach } \\
\text { colorectal }\end{array}$ & $\begin{array}{l}24 \% \text { curative } \\
\text { resection }\end{array}$ & $70.4 \%$ high risk \\
\hline GB Pant, New Delhi ${ }^{[9]}$ & 92 & 50 & $\begin{array}{l}\text { Stomach } \\
\text { Small bowel } \\
\text { Duodenum }\end{array}$ & $80 \% \mathrm{R} 0$ resection & $\begin{array}{l}\text { Nuclear pleomorphism as predictor of } \\
\text { recurrence }\end{array}$ \\
\hline $\begin{array}{l}\text { The Cancer Institute } \\
\text { (WIA), Chennai }{ }^{[10]}\end{array}$ & 24 & 56 & $\begin{array}{l}\text { Stomach } \\
\text { Small intestine } \\
\text { Rectum }\end{array}$ & All metastatic & Common sites of metastases - liver \\
\hline $\begin{array}{l}\text { Kidwai Memorial, } \\
\text { Bengaluru }^{[11]}\end{array}$ & 44 & 56 & $\begin{array}{l}\text { Stomach } \\
\text { Small intestine }\end{array}$ & $\begin{array}{l}52 \% \text { localized at } \\
\text { presentation }\end{array}$ & $65 \%$ high risk \\
\hline $\begin{array}{l}\text { TMH, Mumbai } \\
\text { (nonmetastatic) cohort) }^{[12]}\end{array}$ & 103 & 54 & $\begin{array}{l}\text { Stomach } \\
\text { Duodenum } \\
\text { Jejunum }\end{array}$ & $100 \%$ localized & $\begin{array}{l}59 \% \text { high risk } \\
18 \% \text { intermediate risk } \\
21 \% \text { low risk } \\
2 \% \text { very low risk }\end{array}$ \\
\hline $\begin{array}{l}\text { TMH, Mumbai (metastatic } \\
\text { cohort) }\end{array}$ & 83 & 54 & $\begin{array}{l}\text { Stomach } \\
\text { Small intestine } \\
\text { Duodenum } \\
\text { Rectal }\end{array}$ & All metastatic & Commonest mutation - exon 11 c-kit \\
\hline
\end{tabular}

NIMS - Nizam's Institute of Medical Sciences; CMC - Christian Medical College; GB Pant - Govind Ballabh Pant Institute of Post Graduate Medical Education and Research; TMH - Tata Memorial Hospital 
from the outer muscular layers, their exophytic nature is well captured on a CECT. ${ }^{[22]}$ In specific situations such as in the case of anorectal GISTs, a magnetic resonance imaging may provide additional information beyond a CECT

Positron-emission tomography (PET) provides functional information that may help in staging, especially when combined with morphological information provided by computerized tomography (CT). A PET/CT also helps in differentiating necrotic tissue from viable tissue, recurrent tumor from scar tissue, specifically when assessing response in tumors post therapy. ${ }^{[23]}$ The Choi criteria, a combination of tumor density (15\% change) and modified tumor size $(>10 \%)$, is an excellent criteria for early response evaluation and has prognostic value but is yet to be taken as the standard criteria for response assessment in clinical trials in GIST. ${ }^{[24]}$

c. Pathology - The key to an accurate diagnosis of GIST is the pathological evaluation of a biopsy specimen.

- Gross pathology - GISTs are usually well-circumscribed or multinodular tumor that may develop in any portion of the gut wall, but most GISTs are centered in the submucosa or the muscularis propria. Some tumors are predominantly extramural and extremely large tumors may even extend to or infiltrate into the adjacent organs. On cut sections, the tumors are gray-white and solid with a fleshy appearance and often show hemorrhage, necrosis, or cystic change ${ }^{[25]}$

- Microscopic features - GI stromal tumors are very cellular lesions, with $70 \%$ of cases composed of spindle cells, $20 \%$ of epithelioid cells, and the remainder having a mixed cellular composition. Depending on the cytological features including cellularity, nuclear atypia, mitosis, and necrosis, they can be further categorized into potentially benign and malignant GIST. However, in GIST, tumor size and mitotic count per $50 \mathrm{HPF}$ are regarded as the best predictor of malignant behavior. No other histologic parameter has correlated as strongly with metastatic risk or survival ${ }^{[26]}$

- Immunohistochemistry (IHC) - On IHC, KIT (CD117) expression is a sensitive and specific marker for GIST, with about $95 \%$ of GISTs showing a strong and diffuse cytoplasmic staining for KIT, although some tumors, particularly those with an epithelioid morphology, can show membranous staining. ${ }^{[27]}$ CD117 is a highly sensitive marker of GIST which can be consistently expressed in seminomas, mastocytomas, and granulocytic sarcomas, and rarely, expressed in angiosarcoma, metastatic melanoma, clear cell sarcoma, and the Ewing sarcoma/primitive neuroectodermal tumor family of tumors. ${ }^{[28]}$ DOG1 (discovered on GIST1) is also a synchronously used IHC marker for the diagnosis of GIST. ${ }^{[29]}$ The sensitivity of KIT and DOG1, together, approximates $95 \%$ for the diagnosis of GIST, with $<3 \%$ of GISTs being KIT and DOG1 negative. Importantly, DOG1 stains about one-third of KIT-negative GIST, thereby making it a useful adjunct in the diagnosis of GIST. ${ }^{[30]}$ Other IHC markers which stain positively in GIST include CD34, caldesmon, smooth muscle actin, desmin, S-100 protein, and keratin

- The differential diagnosis for GIST includes smooth muscle tumors, nerve sheath tumors, fibromatoses, inflammatory fibroid polyps, inflammatory myofibroblastic tumors, follicular dendritic cell tumors, and other types of sarcomas.

\section{Principles of Management (Overview)}

Once the diagnosis of GIST is established with adequate pathology and radiology, management is based on expected tumor prognosis and staging. A number of prognostic classification systems have developed over the past two decades, including NIH criteria developed by Fletcher, Goh's modified Armed Forces Institute of Pathology risk criteria, and the Joensuu's modified NIH criteria. ${ }^{[30-33]}$ Table 2 offers a snapshot of the widely used system as proposed by Miettinen. ${ }^{[26,34]}$ A deficit in these scores is their nonrecognition of KIT mutational status in their risk assessment. It is important to note that these classifications are based on a pathological evaluation of completely resected specimens in patients with nonmetastatic GIST.

\section{Surgical Management}

\section{General principles}

Surgery is the primary treatment of choice for patients with localized or potentially resectable GIST lesions. Preoperative histological diagnosis is not mandatory if the diagnosis of GIST is strongly suspected and if it appears to be resectable. Biopsy is necessary to confirm the diagnosis if neoadjuvant imatinib is considered prior to attempted resection in a patient who has a large/locally advanced lesion clinicoradiologically suspected to be a GIST.

The surgical procedure should aim to resect the tumor with histologically negative margins. Segmental or wedge resection to obtain negative margins is often appropriate. On laparotomy/laparoscopy, the abdomen should be thoroughly explored to identify and remove any previously undetected peritoneal metastatic deposits. Although primary GISTs may demonstrate inflammatory adhesions to the surrounding organs, a true invasion is not frequent. GISTs are fragile and should be handled with care to avoid tumor rupture. The goal is to achieve complete gross resection of the tumor with an intact pseudocapsule. Violation of the tumor pseudocapsule causes risk for subsequent tumor seeding into the peritoneum. ${ }^{[35]}$

Lymphadenectomy is not indicated unless enlarged or pathologic nodes are seen on imaging or intraoperatively, as GISTs rarely spread to regional nodes. A macroscopically complete resection with negative or positive microscopic 
Table 2: Rates of progression-free survival for gastrointestinal stromal tumors of the stomach, small intestine, and rectum as per Miettinen's Classification

\begin{tabular}{|c|c|c|c|c|c|}
\hline Tumor size $(\mathrm{cm})$ & Mitotic rate (HPFs) & Gastric & Jejunum/ileum & Duodenum & Rectum \\
\hline$\leq 2$ & $\leq 5 / 50$ & 100 & 100 & 100 & 100 \\
\hline $2-5$ & $\leq 5 / 50$ & 98.1 & 95.7 & 91.7 & 91.5 \\
\hline $5-10$ & $\leq 5 / 50$ & 96.4 & 76 & 66 & 43 \\
\hline$>10$ & $\leq 5 / 50$ & 88 & 48 & & \\
\hline$\leq 2$ & $>5 / 50$ & 100 & 50 & - & 46 \\
\hline $2-5$ & $>5 / 50$ & 84 & 27 & 50 & 48 \\
\hline $5-10$ & $>5 / 50$ & 45 & 15 & 14 & 29 \\
\hline 10 & $>5 / 50$ & 14 & 10 & & \\
\hline
\end{tabular}

margins (R0 or $\mathrm{R} 1$ resection, respectively) is associated with a better prognosis than a macroscopically incomplete excision (R2 excision) ${ }^{\left[{ }^{[3]}\right.}$ Re-resection is generally not indicated for microscopically positive margins on final pathology. The presence of microscopically positive margins (R1) after macroscopic total resection may not confer a worse prognosis. In a review of data from more than 800 patients enrolled in two large North American multi-institutional trials, there was no difference in recurrence-free survival in those who had R1 versus R0 resection. ${ }^{[37]}$ Optimal management after R1 resection is still not well defined and may include re-resection, watchful waiting, and/or systemic therapy.

\section{Extent of surgical resection}

Complete resection with at least a 1-to 2-cm gross margin should be the goal of surgical treatment.

Gastric tumors, the most common location for GIST, typically require only a partial gastrectomy or even gastric wedge resection to achieve these margins. Partial gastrectomy confers the same progression-free survival (PFS) as total gastrectomy but spares the perioperative and postoperative morbidity of the more extensive surgery. GISTs arising from the small intestine and larger bowel (including rectum) often require segmental resection of the involved gut.

\section{Minimally invasive approaches}

Minimally invasive resection of gastric GISTs is comparable to open techniques. A meta-analysis of 19 studies ( $n=1060$ GIST cases) revealed no difference in long-term outcomes of GIST resections using laparotomy and laparoscopy.

Laparoscopic resections of GISTs are associated with decreased blood loss and shorter hospital stays when compared with open surgery. ${ }^{[38,39]}$ Studies have shown the feasibility of resecting larger gastric tumors with excellent oncologic outcomes. ${ }^{[40-42]}$ Current guidelines do not generally recommend laparoscopic resection for tumors $>5 \mathrm{~cm}$ in diameter.

\section{Management of small gastrointestinal stromal tumors}

All GISTs $\geq 2 \mathrm{~cm}$ in size should be resected. However, there is no or limited consensus on the management of smaller GISTs $(<2 \mathrm{~cm})$ and guidelines vary in their recommendations. The natural history of small GISTs, their growth rate, and metastatic potential is unknown. Endoscopic mucosal resection techniques may not be able to provide R0 resections, as GISTs originate in the submucosa. Submucosal dissection technique can be occasionally employed for few small lesions at critical locations or in patients unfit or unwilling for surgery. Gastric GISTs behave less aggressively than the small bowel, colorectal, or GISTs in other locations. Gastric GISTs that are $<2 \mathrm{~cm}$ in diameter and asymptomatic are currently referred to as very small, mini- $(1-2 \mathrm{~cm})$ or micro- $(<1 \mathrm{~cm})$ GISTs. Many of these are found only incidentally on endoscopy, in pathologic specimens after gastric resection, or on autopsy. They generally demonstrate benign clinical behavior. Only those lesions that are found to have high-risk features on EUS (irregular borders, cystic spaces, ulceration, echogenic foci, and internal heterogeneity) are considered to be at risk for progression and are considered for surgery.

Resectable gastrointestinal stromal tumor with a higher risk of perioperative morbidity

If imaging findings which suggest a complex surgical procedure is required (like total gastrectomy with adjacent organs removal), then a multidisciplinary consultation regarding the use of preoperative imatinib as a neoadjuvant therapy to downsize the tumor and to avoid a multivisceral/morbid resection is recommended. Furthermore, large abdominal tumors felt to be at a significant risk of tumor rupture during surgery and can be treated with preoperative imatinib.

The duration of preoperative medical therapy varies from 3 months to 1 year. However, it is generally 6-12 months, which corresponds to the time interval when the maximum degree of tumor shrinkage is achieved.

Unresectable, recurrent, or metastatic gastrointestinal stromal tumor

Imatinib and further TKIs are the primary therapies for metastatic GIST. Surgery is indicated when:

- R0 resection at primary and all metastatic sites is possible

- Limited disease progression refractory to imatinib

- Locally advanced or previously unresectable tumors 
after a favorable response to preoperative imatinib

- Management of symptomatic bleeding, obstruction, or similar local tumor-related symptoms.

\section{Medical Management}

\section{Brief history}

The medical management of GIST revolves around the role of imatinib mesylate (IM, a selective tyrosine-kinase inhibitor of KIT, PDGFRA, and ABL), which was initially used for the treatment of chronic myeloid leukemia with great success. Based on the dramatic response of a heavily pretreated patient with GIST to IM which was published as a brief report in 2001, IM is now almost the universal first line of management for patients who are candidates for systemic treatment. ${ }^{[43]}$

\section{Adjuvant treatment post resection of gastrointestinal stromal tumor}

The treatment of GIST post resection is heavily dependent on the risk of recurrence as assessed by the risk recurrence and prognostic scores previously discussed. Patients classified as very low risk or low risk need no further treatment post resection and should be kept under surveillance/observation

For patients with intermediate-risk GIST (recurrence risk 10\%-24\%), there are differing opinions on the need of adjuvant IM as well as the duration of IM. ${ }^{[42,44,45]}$ Currently, there is a trend toward treating these patients with adjuvant IM for 3 years, though an individualized approach is recommended.

The evidence for the adjuvant treatment of resected GIST with IM was initially evaluated in tumors considered high risk for recurrence with the ACOSOG Z9000 (Alliance) intergroup phase 2 trial. Their definition of "high risk" tumors, i.e., tumor diameter $>10 \mathrm{~cm}$, intraperitoneal tumor rupture, or up to four peritoneal implants (more important from a historic standpoint than currently appropriate or standard), received 1 year of adjuvant IM and showed an improved 1-, 3-, and 5-year overall survival (OS) rate which was 99, 97, and $83 \%$, as compared to historical controls. ${ }^{[46]}$ The current standard of 3 years of adjuvant IM for resected GIST is based on the SSG XVIII Phase III trial, which evaluated 3 years of adjuvant IM versus 1 year. ${ }^{[47]}$ The definition of high risk used in this study was tumors with the longest tumor diameter $>10.0 \mathrm{~cm}$, mitotic count $>10$ mitoses $/ 50 \mathrm{hpf}$, tumor diameter $>5.0 \mathrm{~cm}$, and mitotic count over 5 per hpf or tumor rupture before surgery or at surgery. The study showed an improved 5-year recurrence free survival $(65.6 \%$ vs. $47.9 \% ; P<0.001)$ as well as 5 -year OS $(92.0 \%$ vs. $81.7 \% ; P=0.02)$ with 3 years of IM as opposed to 1 year. Interestingly, the longer duration of IM benefitted exon 11 KIT mutants as opposed to no significant improvement for subsets of patients whose GIST harbored KIT exon 9 mutation or PDGFRA mutations, underlying the importance of mutation testing in GIST. ${ }^{[48]}$ Even in the subset of exon 11 KIT mutants, deletions that affected exon 11 codons 557 and/or 558 benefitted the most with 3 years of IM as opposed other subsets of exon 11 KIT mutants. While 3 years of adjuvant IM should be considered the current standard for resected IM, studies evaluating 5 years of adjuvant IM have been completed showed the feasibility of such an approach, with head-to-head comparison results still awaited. ${ }^{[44,49]}$

There are two specific scenarios where the standard dosing of IM $400 \mathrm{mg}$ as adjuvant needs a mutation-specific personalized approach. First, GISTs harboring the PDGFRA exon 18/D842V mutation (comprising 60\%-70\% of PDGFRA mutants) are considered relatively resistant to IM and current recommendations are for no adjuvant treatment for these mutants. ${ }^{[45,50,51]}$ These mutants are considered to be resistant to other TKIs such as sunitinib and regorafenib as well. Second, KIT exon 9 mutants have better outcomes with IM $800 \mathrm{mg} /$ day dosing in the advanced/metastatic setting and it may be worthwhile considering an increased dose for these patients in the adjuvant setting as well, though there is no firm evidence for the same. ${ }^{[45,52]}$

\section{Neoadjuvant Imatinib in gastrointestinal stromal tumor}

Although neoadjuvant IM has been used since 2003, data regarding the feasibility and efficacy have started emerging only recently. Indications for the use of neoadjuvant IM are yet to standardized, but common scenarios where a neoadjuvant approach with IM is considered are as follows:

- Distal anorectal sphincter complex GIST - for organ and/or sphincter preservation

- Bulky duodenal-pancreatic region GISTs to minimize the extent of multivisceral resections and avoid intraoperative tumor rupture

- Difficult initial location of tumors - gastroesophageal junction, rectum, duodenum

- Marginally resectable GIST to facilitate R0 resection.

The single largest published experience with the use of neoadjuvant IM comes from the pooled data of the European Organisation for Research and Treatment of Cancer (EORTC) Soft Tissue and Bone Sarcoma Group (STBSG) sarcoma group, which evaluated 161 patients with locally advanced nonmetastatic GISTs. Almost $83.2 \%$ of the patients underwent R0 resection with such an approach, with only two patients progressing on neoadjuvant IM. Five-year disease-free survival rates were $65 \%$, with a median OS of 104 months. Patients had received IM for a period of 4-12 months prior to surgical evaluation in this study. ${ }^{[53]}$ The feasible and efficacious use of neoadjuvant IM has also been documented in the Indian setup with large retrospective studies from Tata Memorial Hospital. ${ }^{[13,54]}$

Prospective single-arm studies have also validated the use of neoadjuvant IM. The Apollon phase II study prospectively evaluated 41 patients (locoregionally 
advanced, nonmetastatic) GIST with a median tumor size of $10.8 \mathrm{~cm}$ with 6 months of neoadjuvant IM. R0 resections were performed in $30(n=34)$ patients, with two patients having metastatic disease at resection. The PFS rate at 3 years was $85.2 \%$, which was considered promising in view of the fact that patients were not planned for adjuvant IM. ${ }^{[55]}$ A more recent single-arm phase II study in the Asian population evaluated 56 patients with high-risk gastric GIST and found response rates of $63 \%$ with an R0 resection of $91 \%$ using 6-9 months of IM. Although the median follow-up was only 32 months, 2-year OS and PFS rates were encouraging $98 \%$ and $89 \%$, respectively. ${ }^{[56]}$

While the use of neoadjuvant IM has clinical implications and appeal in select cases of GIST, multiple questions remain to be answered.

\section{Treatment of advanced/metastatic gastrointestinal stromal tumor}

Patients with advanced/metastatic GIST have good median OS. These patients should have a KIT mutation testing done and if required, PDGFRA analysis should also be conducted while planning treatment.

The initial treatment for advanced/metastatic GIST is IM, with a dose of $400 \mathrm{mg} /$ day recommended for KIT exon 11 mutants and $800 \mathrm{mg} /$ day for KIT exon 9 mutants. This is based on a PFS benefit seen with $800 \mathrm{mg} /$ day dosing in KIT exon 9 mutants. ${ }^{[57]}$ It is prudent to consider more frequent clinical and radiological tumor assessments in the early course of treatment for advanced GIST, either with CT or PET-CT scans. The median time to response to IM is 3 months, though a slower rate of responses is also known. Although the Choi criteria is appealing, using response evaluation criteria in solid tumors also provides a fair estimation of response/progression. ${ }^{[58]}$

Treatment with IM should be considered until progression or there are tolerance issues even if a complete response is achieved or in the less common scenario of macroscopic resection of residual disease sites. ${ }^{[59]}$ The median progression-free survival with first-line IM in older series is approximately 18-24 months, though this figure has increased to approximately $30-36$ months in later reports, albeit with smaller sample sizes..$^{[8,19,53,60,61]}$ These differences can be explained by upfront treatment with imatinib in the current era (as opposed to the prior use of ineffective chemotherapy and radiotherapy) as well as reducing tumor size at diagnosis across time periods. Beyond median values, there is a cohort of patients who will remain progression free for 6-10 years on IM alone. ${ }^{[62]}$

An important aspect of the management of advanced/ metastatic GIST is the requirement for continued treatment with IM as opposed to cessation post a specified time duration. The concept of IM cessation after 1 year and 3 years was studied in the BFR14 studies. The results showed that IM interruption after $1 / 3$ years in patients responding to IM resulted in a high risk of rapid progression in patients with advanced GIST. ${ }^{[63,64]}$

Although treatment responses with IM are remarkable, approximately $80 \%$ of patients will progress after a median of 2-3 years due to the development of secondary KIT mutations. ${ }^{[65]}$ Secondary mutations typically occur in the ATP-binding pocket of KIT encoded by exons 13 and 14, and the activation loop (A-loop) encoded by exons 17 and 18. ${ }^{[66]}$ Although there is no robust evidence to suggest KIT mutation-based individualized treatment post progression with IM, an option of repeating a biopsy in such a setting to evaluate mutational status is gaining ground. There is some evidence to suggest that sunitinib has preferentially better action against secondary KIT exon 13/14 mutant GISTs, while regorafenib has superior action against exon 17 mutants. ${ }^{[67,68]}$

Options post progression with IM have emerged with trials confirming the efficacy of drugs such as sunitinib and regorafenib in this scenario. Sunitinib (an oral multitargeted receptor tyrosine kinase inhibitor targeting KIT, PDGFRs, VEGFR-1, VEGFR-2, VEGFR-3, FLT3, and RET) has been shown to improve median time to progression as compared to placebo in the second-line setting (27.3 weeks vs. 6.4 weeks; $P<0.0001)$ in a randomized setting and is currently recommended for the same. ${ }^{[69]}$ Careful monitoring of the side effects with sunitinib is required, considering the increased incidence of fatigue, diarrhea, skin discoloration, and nausea seen with sunitinib as opposed to the usually well-tolerated imatinib. In patients who have progressed on both imatinib and sunitinib, the recommended option for further treatment is regorafenib (oral multikinase inhibitor inhibiting VEGFR1-3, TEK, KIT, RET, RAF1, BRAF, $\mathrm{BRAF}^{\mathrm{V} 600 \mathrm{E}}, \mathrm{PDGFR}$, and FGFR). The GRID study evaluated regorafenib versus placebo in a randomized control Phase III trial and showed an improvement in PFS which was statistically significant (4.8 months vs. 0.9 months; $P<0.0001)$. The most common regorafenib-related adverse events of grade 3 or higher seen in the study were hypertension, hand-foot skin reaction, and diarrhea.

While sequencing of treatment as mentioned above is preferable, options beyond this paradigm also need exploration. A commonly used treatment modality is increased dosing of IM from $400 \mathrm{mg}$ to $800 \mathrm{mg}$ per day. Long-term results of the EORTC-STBSG/AIGTG phase III trial have shown that $17.4 \%$ of patients who had progressed on $400 \mathrm{mg}$ dosing and were administered dose escalated IM, $800 \mathrm{mg}$ per day, remained progression free for $>1$ year. Whether such a benefit is limited to KIT exon 9 mutants or can be generalized across subgroups remains to be seen, but such a strategy can be used as an interim measure in resource-constrained settings. ${ }^{[70]}$ Another strategy is the evaluation of metastasectomy or resection in patients with limited progression. While resection is generally considered in advanced disease in patients responding to 
treatment, retrospective evidence suggests that surgery for limited progression has also shown to lead to a PFS of 6-12 months ${ }^{[71,72]}$ while continuing TKIs.

Other drugs that have been evaluated in patients with progressive GIST with limited benefits include sorafenib, dasatinib, and pazopanib. ${ }^{[73-76]}$

\section{Radiation management}

The role of radiotherapy in the management of GIST is limited, as GIST is traditionally considered a radioresistant tumor. ${ }^{[77]}$ A few scenarios where radiotherapy may be attempted include as follows: ${ }^{[78]}$

- Radiotherapy of metastases for palliation of local symptoms

- Radiotherapy of focally progressing lesions, with the aim of overcoming emergent resistant clones

- Definitive radiotherapy alternative to surgery in localized GIST in elderly patients with comorbidities or in case of unresectable tumors.

\section{Special Situations in Gastrointestinal Stromal} Tumor

Syndromes associated with gastrointestinal stromal tumor

GIST is a predominantly sporadic disease, but since 1998, germ line mutations with familial predisposition to GIST have been identified. ${ }^{[79,80]}$

- Neurofibromatosis type 1 (von Recklinghausen's disease)

- Carney-Stratakis Syndrome

- Carney's triad

Available data suggest that GISTs associated with the above-mentioned hereditary syndromes are generally less sensitive to treatment with IM. ${ }^{[0]}$

Treatment of advanced gastrointestinal stromal tumor with platelet-derived growth factor receptor alpha mutations

Patients with PDGFRA mutations are seen in 5\%-15\% of localized GISTs and $1 \%-3 \%$ of advanced GISTs, likely because of the better prognosis of these GISTs when presenting with localized diseas e. ${ }^{[81,82]}$ While patients with resected disease and harboring PDGFRA D842V mutations are recommended not to receive adjuvant IM, there are no such recommendations for patients with advanced disease. Two large retrospective studies have been conducted solely focusing on the outcomes in PDGFRA-mutant tumors. The first study comprised data collated from investigators attached to members of the EORTC-STBSG, the French Sarcoma Group (GSF-GETO), the Italian Sarcoma Group, and the Spanish Sarcoma Groups (GEIS). ${ }^{[83]}$ Fighty-eight patients were evaluated, of whom 32 patients $(55 \%)$ had PDGFRA-D842V substitutions, whereas 17 (29\%) had mutations affecting other codons of exon 18 and nine
Table 3: Stage-wise overall survival in gastrointestinal stromal tumor

\begin{tabular}{lc}
\hline Stage & 5-year overall survival (\%) \\
\hline Low risk and intermediate risk & 91 \\
resected GIST & 74 \\
High-risk resected GIST & 48 \\
Metastatic GIST &
\end{tabular}

patients $(16 \%)$ had mutations in other exons (exon 12 and exon 4). The study clearly showed that none of the 31 evaluable patients with $\mathrm{D} 842 \mathrm{~V}$ mutations had a response to IM, while responses were seen in the non-D842V subgroup. This also translated into markedly different PFS and OS between the two mutant cohorts. The second study comprising 71 patients from the Netherlands and United States suggested that a small cohort of patients with D842V mutants respond to IM, though such patients would need frequent monitoring if started on IM. ${ }^{[84]}$

Based on the available evidence, a majority of patients with PDGFRA non-D842V respond to and should be treated with IM, while for patients with D842V mutations, the appropriate line of management at this juncture is still to be elucidated. Treatment with second-line TKIs may be attempted. Avapritinib, a potent and selective kinase inhibitor with broad activity against oncogenic KIT/ PDGFRA mutants, including PDGFRA, has recently shown activity in pretreated unresectable PDGFRA D842V and KIT-mutated GISTs and is likely to become an option for treatment in this subset of patients. ${ }^{[85]}$

\section{Stage-wise Prognosis with Current Management}

The survival of patients with GIST has improved markedly over the past two decades as understanding of the disease biology has grown along with improvement in surgical techniques and the increasing benefits with imatinib and other TKIs. The expected survival for patients receiving multimodality management in the current era is detailed in Table 3. ${ }^{[86]}$

\section{Financial support and sponsorship}

Nil.

\section{Conflicts of interest}

There are no conflicts of interest.

\section{References}

1. Joensuu H, Hohenberger P, Corless CL. Gastrointestinal stromal tumour. Lancet 2013;382:973-83.

2. Beham AW, Schaefer IM, Schüler P, Cameron S, Ghadimi BM. Gastrointestinal stromal tumors. Int $\mathrm{J}$ Colorectal Dis 2012;27:689-700.

3. Lanke G, Lee JH. How best to manage gastrointestinal stromal tumor. World J Clin Oncol 2017;8:135-44.

4. Chabot B, Stephenson DA, Chapman VM, Besmer P, Bernstein A. The proto-oncogene c-kit encoding a transmembrane 
tyrosine kinase receptor maps to the mouse W locus. Nature 1988;335:88-9.

5. Hirota $\mathrm{S}$, Isozaki $\mathrm{K}$, Moriyama $\mathrm{Y}$, Hashimoto $\mathrm{K}$, Nishida $\mathrm{T}$, Ishiguro $\mathrm{S}$, et al. Gain-of-function mutations of c-kit in human gastrointestinal stromal tumors. Science 1998;279:577-80.

6. Søreide K, Sandvik OM, Søreide JA, Giljaca V, Jureckova A, Bulusu VR. Global epidemiology of gastrointestinal stromal tumours (GIST): A systematic review of population-based cohort studies. Cancer Epidemiol 2016;40:39-46.

7. Suresh Babu MC, Chaudhuri T, Babu KG, Lakshmaiah KC, Lokanatha D, Jacob LA, et al. Metastatic gastrointestinal stromal tumor: A regional cancer center experience of 44 cases. South Asian J Cancer 2017;6:118-21.

8. Bose S, Ramaswamy A, Sahu A, Shetty O, Zanwar SS, Mirani J, et al. Clinical practice and outcomes in advanced gastrointestinal stromal tumor: Experience from an Indian tertiary care center. South Asian J Cancer 2017;6:110-2.

9. Varshney VK, Gupta RK, Saluja SS, Tyagi I, Mishra PK, Batra VV. Analysis of clinicopathological and immunohistochemical parameters and correlation of outcomes in gastrointestinal stromal tumors. Indian J Cancer 2019;56:135-43.

10. Lakshmi VA, Chacko RT, Kurian S. Gastrointestinal stromal tumors: A 7-year experience from a tertiary care hospital. Indian J Pathol Microbiol 2010;53:628-33.

11. Rajappa S, Muppavarapu KM, Uppin S, Digumarti R. Gastrointestinal stromal tumors: A single institution experience of 50 cases. Indian J Gastroenterol 2007;26:225-9.

12. Cyriac S, Rajendranath R, Sagar TG. Gastrointestinal stromal tumor: Analysis of outcome and correlation with c-kit status in Indian population. Indian J Cancer 2014;51:35-9.

13. Ramaswamy A, Jain D, Sahu A, Ghosh J, Prasad P, Deodhar K, et al. Neoadjuvant imatinib: Longer the better, need to modify risk stratification for adjuvant imatinib. J Gastrointest Oncol 2016;7:624-31.

14. Rubin BP, Singer S, Tsao C, Duensing A, Lux ML, Ruiz R, et al. KIT activation is a ubiquitous feature of gastrointestinal stromal tumors. Cancer Res 2001;61:8118-21.

15. Corless CL, Fletcher JA, Heinrich MC. Biology of gastrointestinal stromal tumors. J Clin Oncol 2004;22:3813-25.

16. Martín J, Poveda A, Llombart-Bosch A, Ramos R, López-Guerrero JA, García del Muro J, et al. Deletions affecting codons 557-558 of the c-KIT gene indicate a poor prognosis in patients with completely resected gastrointestinal stromal tumors: A study by the Spanish Group for Sarcoma Research (GEIS). J Clin Oncol 2005;23:6190-8.

17. Ramaswamy A, Bal M, Swami R, Shetty O, Bose S, Pai T, et al. Early outcomes of exon 11 mutants in GIST treated with standard dose Imatinib. Ann Transl Med 2017;5:134.

18. Patrikidou A, Domont J, Chabaud S, Ray-Coquard I, Coindre JM, Bui-Nguyen B, et al. Long-term outcome of molecular subgroups of GIST patients treated with standard-dose imatinib in the BFR14 trial of the French Sarcoma Group. Eur J Cancer 2016;52:173-80.

19. Heinrich MC, Rankin C, Blanke CD, Demetri GD, Borden EC, Ryan CW, et al. Correlation of Long-term Results of Imatinib in Advanced Gastrointestinal Stromal Tumors With Next-Generation Sequencing Results: Analysis of Phase 3 SWOG Intergroup Trial S0033. JAMA Oncol 2017;3:944-52.

20. Park CH, Kim EH, Jung DH, Chung H, Park JC, Shin SK, et al. Impact of periodic endoscopy on incidentally diagnosed gastric gastrointestinal stromal tumors: Findings in surgically resected and confirmed lesions. Ann Surg Oncol 2015;22:2933-9.

21. Yamabe A, Irisawa A, Bhutani MS, Shibukawa G, Abe Y, Saito A, et al. Usefulness of endoscopic ultrasound-guided fine-needle aspiration with a forward-viewing and curved linear-array echoendoscope for small gastrointestinal subepithelial lesions. Endosc Int Open 2015;3:E161-4.

22. Imaging of Gastrointestinal Stromal Tumors: From Diagnosis to Evaluation of Therapeutic Response. Available from: http:// ar.iiarjournals.org/content/36/6/2639.full. [Last accessed on 2018 Oct 16].

23. Imaging Therapy Response of Gastrointestinal Stromal Tumors (GIST) with FDG PET, CT and MRI: A Systematic Review SpringerLink. Available from: https://link.springer. com/article/10.1007/s40336-017-0229-8. [Last accessed on 2018 Oct 16].

24. Choi H. Response evaluation of gastrointestinal stromal tumors. Oncologist 2008;13 Suppl 2:4-7.

25. Laurini JA, Carter JE. Gastrointestinal stromal tumors: A review of the literature. Arch Pathol Lab Med 2010;134:134-41.

26. Miettinen M, Lasota J. Gastrointestinal stromal tumors: Review on morphology, molecular pathology, prognosis, and differential diagnosis. Arch Pathol Lab Med 2006;130:1466-78.

27. Hornick JL, Fletcher CD. The role of KIT in the management of patients with gastrointestinal stromal tumors. Hum Pathol 2007;38:679-87.

28. Charville GW, Longacre TA. Surgical Pathology of Gastrointestinal Stromal Tumors: Practical Implications of Morphologic and Molecular Heterogeneity for Precision Medicine. Adv Anat Pathol 2017;24:336-53.

29. Miettinen M, Wang ZF, Lasota J. DOG1 antibody in the differential diagnosis of gastrointestinal stromal tumors: A study of 1840 cases. Am J Surg Pathol 2009;33:1401-8.

30. Liegl B, Hornick JL, Corless CL, Fletcher CD. Monoclonal antibody DOG1.1 shows higher sensitivity than KIT in the diagnosis of gastrointestinal stromal tumors, including unusual subtypes. Am J Surg Pathol 2009;33:437-46.

31. Fletcher CD, Berman JJ, Corless C, Gorstein F, Lasota J, Longley BJ, et al. Diagnosis of gastrointestinal stromal tumors: A consensus approach. Hum Pathol 2002;33:459-65.

32. Goh BK, Chow PK, Yap WM, Kesavan SM, Song IC, Paul PG, et al. Which is the optimal risk stratification system for surgically treated localized primary GIST? Comparison of three contemporary prognostic criteria in 171 tumors and a proposal for a modified Armed Forces Institute of Pathology risk criteria. Ann Surg Oncol 2008;15:2153-63.

33. Joensuu H. Risk stratification of patients diagnosed with gastrointestinal stromal tumor. Hum Pathol 2008;39:1411-9.

34. Miettinen M, Lasota J. Gastrointestinal stromal tumors: Pathology and prognosis at different sites. Semin Diagn Pathol 2006;23:70-83.

35. Demetri GD, von Mehren M, Antonescu CR, DeMatteo RP, Ganjoo KN, Maki RG, et al. NCCN Task Force report: Update on the management of patients with gastrointestinal stromal tumors. J Natl Compr Canc Netw 2010;8 Suppl 2:S1-41.

36. DeMatteo RP, Lewis JJ, Leung D, Mudan SS, Woodruff JM, Brennan MF. Two hundred gastrointestinal stromal tumors: Recurrence patterns and prognostic factors for survival. Ann Surg 2000;231:51-8.

37. McCarter MD, Antonescu CR, Ballman KV, Maki RG, Pisters PW, Demetri GD, et al. Microscopically positive margins for primary gastrointestinal stromal tumors: Analysis of risk factors and tumor recurrence. J Am Coll Surg 2012;215:53-9.

38. MacArthur KM, Baumann BC, Nicholl MB. Laparoscopic Versus Open Resection for Gastrointestinal Stromal Tumors (GISTs). J Gastrointest Cancer 2017;48:20-4. 
39. $\mathrm{Hu}$ J, Or BH, Hu K, Wang ML. Comparison of the post-operative outcomes and survival of laparoscopic versus open resections for gastric gastrointestinal stromal tumors: A multi-center prospective cohort study. Int J Surg 2016;33 Pt A: 65-71.

40. Nguyen SQ, Divino CM, Wang JL, Dikman SH. Laparoscopic management of gastrointestinal stromal tumors. Surg Endosc 2006;20:713-6.

41. Nakamori M, Iwahashi M, Nakamura M, Tabuse K, Mori K, Taniguchi $\mathrm{K}$, et al. Laparoscopic resection for gastrointestinal stromal tumors of the stomach. Am J Surg 2008;196:425-9.

42. Bischof DA, Kim Y, Dodson R, Carolina Jimenez M, Behman R, Cocieru A, et al. Open versus minimally invasive resection of gastric GIST: A multi-institutional analysis of short- and long-term outcomes. Ann Surg Oncol 2014;21:2941-8.

43. Joensuu H, Roberts PJ, Sarlomo-Rikala M, Andersson LC, Tervahartiala P, Tuveson D, et al. Effect of the tyrosine kinase inhibitor STI571 in a patient with a metastatic gastrointestinal stromal tumor. N Engl J Med 2001;344:1052-6.

44. Cameron S. Long-term adjuvant treatment of gastrointestinal stromal tumors (GIST) with imatinib-a comment and reflection on the PERSIST-5 study. Transl Gastroenterol Hepatol 2018;3:16.

45. Casali PG, Abecassis N, Aro HT, Bauer S, Biagini R, Bielack S, et al. Gastrointestinal stromal tumours: ESMO-EURACAN Clinical Practice Guidelines for diagnosis, treatment and follow-up. Ann Oncol 2018;29:iv68-iv78.

46. DeMatteo RP, Ballman KV, Antonescu CR, Corless C, Kolesnikova V, von Mehren M, et al. Long-term results of adjuvant imatinib mesylate in localized, high-risk, primary gastrointestinal stromal tumor: ACOSOG Z9000 (Alliance) intergroup phase 2 trial. Ann Surg 2013;258:422-9.

47. Joensuu H, Eriksson M, Sundby Hall K, Hartmann JT, Pink D, Schütte $\mathrm{J}$, et al. One vs three years of adjuvant imatinib for operable gastrointestinal stromal tumor: A randomized trial. JAMA 2012;307:1265-72.

48. Joensuu H, Wardelmann E, Sihto H, Eriksson M, Sundby Hall K, Reichardt A, et al. Effect of KIT and PDGFRA mutations on survival in patients with gastrointestinal stromal tumors treated with adjuvant imatinib: An exploratory analysis of a randomized clinical trial. JAMA Oncol 2017;3:602-9.

49. Raut CP, Espat NJ, Maki RG, Araujo DM, Williams TF, Wolff JE, et al. Extended treatment with adjuvant imatinib (IM) for patients (pts) with high-risk primary gastrointestinal stromal tumor (GIST): The PERSIST-5 study. J Clin Oncol 2017;35 Suppl 15:11009.

50. Corless CL, Schroeder A, Griffith D, Town A, McGreevey L, Harrell $\mathrm{P}$, et al. PDGFRA mutations in gastrointestinal stromal tumors: Frequency, spectrum and in vitro sensitivity to imatinib. J Clin Oncol 2005;23:5357-64.

51. Heinrich MC, Corless CL, Demetri GD, Blanke CD, von Mehren M, Joensuu $\mathrm{H}$, et al. Kinase mutations and imatinib response in patients with metastatic gastrointestinal stromal tumor. J Clin Oncol 2003;21:4342-9.

52. Heinrich MC, Owzar K, Corless CL, Hollis D, Borden EC, Fletcher $\mathrm{CD}$, et al. Correlation of kinase genotype and clinical outcome in the North American Intergroup Phase III Trial of imatinib mesylate for treatment of advanced gastrointestinal stromal tumor: CALGB 150105 Study by Cancer and Leukemia Group B and Southwest Oncology Group. J Clin Oncol 2008;26:5360-7.

53. Rutkowski $\mathrm{P}$, Gronchi A, Hohenberger $\mathrm{P}$, Bonvalot $\mathrm{S}$, Schöffski P, Bauer S, et al. Neoadjuvant imatinib in locally advanced gastrointestinal stromal tumors (GIST): The EORTC STBSG experience. Ann Surg Oncol 2013;20:2937-43.
54. Ramaswamy A, Ostwal V, Shetty O, Sahu A, Paul D, Pai T, et al. Neoadjuvant Imatinib in Locally Advanced Gastrointestinal stromal Tumours, Will Kit Mutation Analysis Be a Pathfinder? J Gastrointest Cancer 2016;47:381-8.

55. Hohenberger $\mathrm{P}$, Langer $\mathrm{C}$, Wendtner CM, Hohenberger W, Pustowka A, Wardelmann E, et al. Neoadjuvant treatment of locally advanced GIST: Results of APOLLON, a prospective, open label phase II study in KIT-or PDGFRA-positive tumors. J Clin Oncol 2012;30 Suppl 15:10031.

56. Kurokawa Y, Yang HK, Cho $\mathrm{H}$, Ryu MH, Masuzawa $\mathrm{T}$, Park SR, et al. Phase II study of neoadjuvant imatinib in large gastrointestinal stromal tumours of the stomach. Br J Cancer 2017; 117:25-32.

57. Gastrointestinal Stromal Tumor Meta-Analysis Group (MetaGIST). Comparison of two doses of imatinib for the treatment of unresectable or metastatic gastrointestinal stromal tumors: A meta-analysis of 1,640 patients. J Clin Oncol 2010;28:1247-53.

58. Dudeck O, Zeile M, Reichardt P, Pink D. Comparison of RECIST and Choi criteria for computed tomographic response evaluation in patients with advanced gastrointestinal stromal tumor treated with sunitinib. Ann Oncol 2011;22:1828-33.

59. Nishida T, Blay JY, Hirota S, Kitagawa Y, Kang YK. The standard diagnosis, treatment, and follow-up of gastrointestinal stromal tumors based on guidelines. Gastric Cancer 2016;19:3-14.

60. Le Cesne A, Van Glabbeke M, Verweij J, Casali PG, Findlay M, Reichardt $\mathrm{P}$, et al. Absence of progression as assessed by response evaluation criteria in solid tumors predicts survival in advanced GI stromal tumors treated with imatinib mesylate: The intergroup EORTC-ISG-AGITG phase III trial. J Clin Oncol 2009;27:3969-74.

61. Yeh CN, Chen YY, Tseng JH, Chen JS, Chen TW, Tsai CY, et al. Imatinib Mesylate for Patients with Recurrent or Metastatic Gastrointestinal Stromal Tumors Expressing KIT: A Decade Experience from Taiwan. Transl Oncol 2011;4:328-35.

62. Blanke CD, Demetri GD, von Mehren M, Heinrich MC, Eisenberg B, Fletcher JA, et al. Long-term results from a randomized phase II trial of standard- versus higher-dose imatinib mesylate for patients with unresectable or metastatic gastrointestinal stromal tumors expressing KIT. J Clin Oncol 2008;26:620-5.

63. Blay JY, Le Cesne A, Ray-Coquard I, Bui B, Duffaud F, Delbaldo $\mathrm{C}$, et al. Prospective multicentric randomized phase III study of imatinib in patients with advanced gastrointestinal stromal tumors comparing interruption versus continuation of treatment beyond 1 year: The French Sarcoma Group. J Clin Oncol 2007;25:1107-13.

64. Le Cesne A, Ray-Coquard I, Bui BN, Adenis A, Rios M, Bertucci $\mathrm{F}$, et al. Discontinuation of imatinib in patients with advanced gastrointestinal stromal tumours after 3 years of treatment: An open-label multicentre randomised phase 3 trial. Lancet Oncol 2010;11:942-9.

65. Liegl B, Kepten I, Le C, Zhu M, Demetri GD, Heinrich MC, et al. Heterogeneity of kinase inhibitor resistance mechanisms in GIST. J Pathol 2008;216:64-74.

66. Oppelt PJ, Hirbe AC, Van Tine BA. Gastrointestinal stromal tumors (GISTs): Point mutations matter in management, a review. J Gastrointest Oncol 2017;8:466-73.

67. Prenen H, Cools J, Mentens N, Folens C, Sciot R, Schöffski P, et al. Efficacy of the kinase inhibitor SU11248 against gastrointestinal stromal tumor mutants refractory to imatinib mesylate. Clin Cancer Res 2006;12:2622-7.

68. Yeh $\mathrm{CN}$, Chen MH, Chen YY, Yang CY, Yen CC, Tzen CY, et al. A phase II trial of regorafenib in patients with metastatic 
and/or a unresectable gastrointestinal stromal tumor harboring secondary mutations of exon 17. Oncotarget 2017;8:44121-30.

69. Demetri GD, van Oosterom AT, Garrett CR, Blackstein ME, Shah $\mathrm{MH}$, Verweij $\mathrm{J}$, et al. Efficacy and safety of sunitinib in patients with advanced gastrointestinal stromal tumour after failure of imatinib: A randomised controlled trial. Lancet 2006;368:1329-38.

70. Casali PG, Zalcberg J, Le Cesne A, Reichardt P, Blay JY, Lindner LH, et al. Ten-Year Progression-Free and Overall Survival in Patients With Unresectable or Metastatic GI Stromal Tumors: Long-Term Analysis of the European Organisation for Research and Treatment of Cancer, Italian Sarcoma Group, and Australasian Gastrointestinal Trials Group Intergroup Phase III Randomized Trial on Imatinib at Two Dose Levels. J Clin Oncol 2017;35:1713-20.

71. DeMatteo RP, Maki RG, Singer S, Gonen M, Brennan MF, Antonescu CR. Results of tyrosine kinase inhibitor therapy followed by surgical resection for metastatic gastrointestinal stromal tumor. Ann Surg 2007;245:347-52.

72. Hasegawa J, Kanda T, Hirota S, Fukuda M, Nishitani A, Takahashi T, et al. Surgical interventions for focal progression of advanced gastrointestinal stromal tumors during imatinib therapy. Int J Clin Oncol 2007;12:212-7.

73. Park SH, Ryu MH, Ryoo BY, Im SA, Kwon HC, Lee SS, et al. Sorafenib in patients with metastatic gastrointestinal stromal tumors who failed two or more prior tyrosine kinase inhibitors: A phase II study of Korean gastrointestinal stromal tumors study group. Invest New Drugs 2012;30:2377-83.

74. Montemurro M, Cioffi A, Dômont J, Rutkowski P, Roth AD, von Moos R, et al. Long-term outcome of dasatinib first-line treatment in gastrointestinal stromal tumor: A multicenter, 2-stage phase 2 trial (Swiss Group for Clinical Cancer Research 56/07). Cancer 2018;124:1449-54.

75. Mir O, Cropet C, Toulmonde M, Cesne AL, Molimard M, Bompas E, et al. Pazopanib plus best supportive care versus best supportive care alone in advanced gastrointestinal stromal tumours resistant to imatinib and sunitinib (PAZOGIST): A randomised, multicentre, open-label phase 2 trial. Lancet Oncol 2016;17:632-41.

76. Ramaswamy A, Pande N, Shetty O, Shetty N, Gupta S, Ostwal V. Pazopanib in metastatic multiply treated progressive gastrointestinal stromal tumors: Feasible and efficacious.
J Gastrointest Oncol 2016;7:638-43.

77. Crosby JA, Catton CN, Davis A, Couture J, O'Sullivan B, Kandel R, et al. Malignant gastrointestinal stromal tumors of the small intestine: A review of 50 cases from a prospective database. Ann Surg Oncol 2001;8:50-9.

78. Gatto L, Nannini M, Saponara M, Di Scioscio V, Beltramo G, Frezza GP, et al. Radiotherapy in the management of gist: State of the art and new potential scenarios. Clin Sarcoma Res 2017;7:1

79. Nishida T, Hirota S, Taniguchi M, Hashimoto K, Isozaki K, Nakamura H, et al. Familial gastrointestinal stromal tumours with germline mutation of the KIT gene. Nat Genet 1998;19:323-4.

80. Postow MA, Robson ME. Inherited gastrointestinal stromal tumor syndromes: Mutations, clinical features, and therapeutic implications. Clin Sarcoma Res 2012;2:16.

81. Wozniak A, Rutkowski P, Piskorz A, Ciwoniuk M, Osuch C, Bylina E, et al. Prognostic value of KIT/PDGFRA mutations in gastrointestinal stromal tumours (GIST): Polish Clinical GIST Registry experience. Ann Oncol 2012;23:353-60.

82. Debiec-Rychter M, Sciot R, Le Cesne A, Schlemmer M, Hohenberger P, van Oosterom AT, et al. KIT mutations and dose selection for imatinib in patients with advanced gastrointestinal stromal tumours. Eur J Cancer 2006;42:1093-103.

83. Cassier PA, Fumagalli E, Rutkowski P, Schöffski P, Van Glabbeke M, Debiec-Rychter M, et al. Outcome of patients with platelet-derived growth factor receptor alpha-mutated gastrointestinal stromal tumors in the tyrosine kinase inhibitor era. Clin Cancer Res 2012;18:4458-64.

84. Farag S, Somaiah N, Choi H, Heeres B, Wang WL, van Boven H, et al. Clinical characteristics and treatment outcome in a large multicentre observational cohort of PDGFRA exon 18 mutated gastrointestinal stromal tumour patients. Eur J Cancer 2017;76:76-83.

85. Heinrich MC, Jones RL, von Mehren M, Bauer S, Kang Y-K, Schoffski P, et al. Clinical activity of avapritinib in $\geq$ fourth-line $(4 \mathrm{~L}+)$ and PDGFRA Exon 18 gastrointestinal stromal tumors (GIST). J Clin Oncol 2019;37 Suppl 15:11022.

86. Survival Rates for Gastrointestinal Stromal Tumors. Available from: https:/www.cancer.org/cancer/ gastrointestinal-stromal-tumor/detection-diagnosis-staging/ survival-rates.html. [Last accessed on 2018 Oct 24]. 